\title{
A CHANGE VECTOR ANALYSIS METHOD TO MONITOR DROUGHT USING LANDSAT DATA
}

\author{
R. Ebrahimian ${ }^{1, *}$, A. Alesheikh ${ }^{2}$ \\ ${ }^{1}$ Department of GIS/RS, Science and Research Branch, Islamic Azad University, Tehran, Iran - roza_ebrahimian@yahoo.com \\ 2 Department of Geospatial Information Systems, Faculty of Geodesy and Geomatics Engineering, K. N. Toosi University of \\ Technology, Tehran, Iran - alesheikh@kntu.ac.ir
}

KEY WORDS: Drought, Evapotranspiration, Change Vector Analysis, SEBAL, Najaf Abad basin, Landsat.

\begin{abstract}
:
Drought has always been a heavy financial burden on a country's economy. To mitigate the impacts of an ongoing drought, spatial information on high risk areas are required. Therefore, the aim of this study is to identify the areas prone to drought in order to minimize the damages through a proper management policy. To achieve this goal, the actual evapotranspiration is considered. The rate of actual evapotranspiration was measured in Najaf Abad using the Surface Energy Balance Algorithm for Land (SEBAL) on Landsat ATM ${ }^{+}$ images. To present and test the changes in drought, the Change Vector Analysis (CVA) technique was applied to multi-temporal data to compare the differences in the time-trajectory of the tasselled cap intestines and brightness for two time periods 1995 to 2008 - 2008 to 2015. The images were processed using ArcGIS 10.3 and ERDAS Imagine $8.6^{\mathrm{TM}}$ software. The results indicated that the changed area is 9691.41 hectare and the unchanged is 49335.2 hectare between 1995 to 2008 . The area of the changed pixels between 2008 and $2015,3 \%$ is higher than the area of the change pixels in 1995 until 2008. In more than 3-quarter of the study area, the value of evapotranspiration has not changed. The proposed method demonstrated immense potentials in monitoring drought change dynamics especially when complemented with field studies.
\end{abstract}

\section{INTRODUCTION}

Drought, as a natural hazard, can bring tremendous economic losses and significant social and environmental impacts to communities across the globe. To provide planning for drought preparedness, change detection of drought is required (Xinyu Fu, 2013). For change detection of drought, remotely sensed data plays a vital role. The image can be used to determine evapotranspiration changes (Wen, 2009).

Several studies have found that the frequency, magnitude and spatio-temporal distribution of droughts have significantly been increased in many regions of Iran. Yet, most of the methods used in detecting trends in change of hydrological extremes are based on characteristics that, cannot be directly used in decision making (Beatriz Quesada-Montano, 2017). The selection of an appropriate method for studying evapotranspiration changes caused by droughts is still an ongoing research, since, different types of change due to droughts can occur concurrently and may be interpreted in different ways. There are four change detection techniques that are mostly used in monitoring changes, namely; image differencing, image rationing, image regression and change vector analysis (CVA), (Murat Özyavuz 2011). Among them, CVA is a powerful change detection algorithm and can be used to detect evapotranspiration changes with respect to droughts in long-term data analysis( Bayarjargal, 2006). CVA, developed in the 80s (Malila, 1980) and was originally proposed by Malila and further extended by the pioneering studies of Lambin, Strahlers and Ehrlich (Arnon Karnieli, 2014).

CVA estimates the direction of changes between two dates for each pixel of an image. Therefore, there is no need for an image classification to be performed in advance. CVA needs two (or more) spectral characteristics (bands or spectral features) of the surface (Bitelli, 2017) as its input. In CVA, each pixel is represented by a point in a multidimensional space (spectral and temporal). The CVA technique enables the user to stratify different types of change with respect to land use or land cover dynamics in a specific region.

We used CVA in this study, because spectral characteristics of the type of analysis are based primarily on remote sensing images. In addition to the change detection, CVA can present the distribution of information and the types of feature changed. Also It can make direction and intensity maps (Alesheikh et al. 2007) \& (Song Xiaolu, 2011). Here, we analysed the changes in droughts based on CVA, since it produces the magnitude and direction maps that can present the amount and intensity of change in different locations.

\section{LITERATURE REVIEW}

Some scholars have elaborated on the application of CVA through computing direction and magnitude of changes; while Frank Thonfeld et al. (2016) compared Robust Change Vector Analysis (RCVA) and CVA to scientifically discuss the advantages of each method. Their analysis showed that RCVA results in fewer false negatives as well as false positives than CVA under similar test conditions. They claimed that, RCVA is a powerful technique which can be used to reduce spurious changes in bi-temporal change detection analyses based on highor very-high spatial resolution imagery (Thonfeldab, 2016). According to this research, RCVA is more powerful technique than CVA but it is used for high spatial resolution. In this paper

\footnotetext{
* Corresponding author
} 
Landsat was used. Landsat data is one of the lowest resolutions between other Satellite data.

Vahidnia et all. (2011), proposed a new model that considered both aspects of static and dynamic behaviors of spreadable spatio-temporal in cellular automata (CA) modeling. They focused on the estimation of forest fire growth as an important case study for decision makers. A two-dimensional cellular representation of the combustion of heterogeneous fuel types and density on non-flat terrain were successfully linked with dynamic wind and slope impact. The validation of the simulation on experimental data indicated a relatively realistic head-fire shape. Further investigations showed that the results obtained using the dynamic controlling with GA in the absence of static modeling with ANFIS were unacceptable (Vahidnia 2011).

Jafari et all.(2016), used a model which combines a logistic regression model, Markov chain, together with cellular automata based modeling for simulating future urban growth and development in the Gilan Province, Iran. The model is calibrated based on data beginning in 1989 and ending in 2013 and is applied in making predictions for the years 2025 and 2037. These results demonstrate the capacity of the integrated model in establishing comparisons with urban plans and their utility to explain both the volume and constraints of urban growth. It is beneficial to apply the integrated approach in urban dynamic assessment through land use modeling with respect to spatiotemporal representation in distinct urban development formats (Jafari 2016).

Salih et al. (2017), assessed various techniques for environmental monitoring with emphasis on desertification. He tried to model and map the status and the rate of desertification processes as well as land cover changes in semi-arid areas in White Nile State (Sudan) by using multi-temporal imagery of the Landsat satellite TM (1987), TM (2000), and ETM+ (2014) respectively. They also discussed and evaluated the efficiency of the adapted methodologies in monitoring the land degradation processes and changes in the arid and semi-arid regions (Salih, 2017).

Ye et al. (2016) proposed a novel algorithm named "Three-layer SVDD Fusion (TLSF)" for targeted change detection that is based on Support Vector Domain Description (SVDD). Their experimental results of two case studies showed that the overall accuracy of the proposed algorithm is superior compared to applying SVDD to change vector analysis and post-classification comparison (SuYe 2016).

\section{PROPOSED METHOD}

\subsection{Study area}

Najaf Abad basin is located in Isfahan province. It has more than 14000 wells. So, it is one of the most important basins in this province. Recently, the groundwater level of it has been dropped. So we choose this basin for studying.

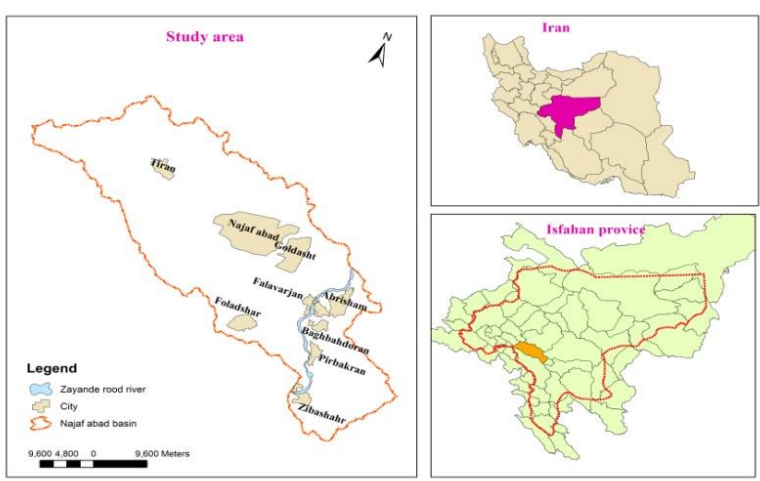

Figure 1. Najaf abad basin

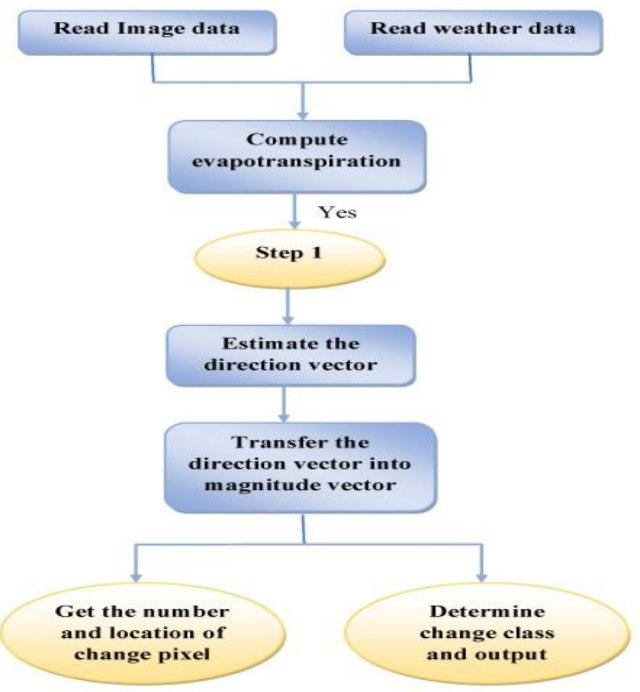

Figure 2. Flowchart of method

\subsection{Image pre-processing}

3.2.1 Geometric correctionPre-processing of each image is very important to compute correct change detection. Because of some elements, such as soil moisture, vegetation phenology, atmospheric conditions, sun angle and sensor parameters which impact on pixel spectral changes. They must be removed to make sure that the changes are only caused by surface features changes. One way that helps us to remove these effects on the pixels is geometric correction. Landsat images have geometric correction so we don't need to it.

\subsubsection{Topography correction}

In this study, Lambert method using Digital elevation model is used in topography correction of images to delete some factors.

\subsection{Change vector analysis}

In this study, 30 years of evapotranspiration data from 1995 to 2015 , have been processed. Then, where change has occurred in the pair images, the relationship between the corresponding pixels pair can be characterized by a change vector with a measurable strength. Step 1 will distinguish changed pixels from non-changed ones.

First, we use change vectors to indicate all the image pixels, which can be seen in (1):

$|\mathrm{C}|=\sqrt{\sum(\text { Iref }- \text { Iy)2 }}$

$\mathrm{I}_{\mathrm{ref}}=$ image pixel vector of $\mathrm{t} 1$ period;

$\mathrm{I}_{\mathrm{y}}=$ image pixel vector of $\mathrm{t} 2$ period.

Then Change magnitude is measured by the Euclidean distance between pixel measurement at time 1 to the corresponding pixel measurement at time 2.

$\mathrm{S}=[$ Iref $-\mathrm{Iy}]$

In equation 2, direction of change vector time is generally created with Evapotranspirationness of 2008 and 2015. S can be positive or negative.$S$ indicates the nature of the change in evapotranspiration (Koch, 2008). 


\section{RESULTS}

\subsection{Analysis of intensity of the change image 1995/2008}

The change image referring to the years 1995 and 2008 (Figure

3) shows an intensive dynamics related to the clear-cut of evapotranspiration primary, in a period characterized by the advancement of land occupation activities (agriculture) in the red.

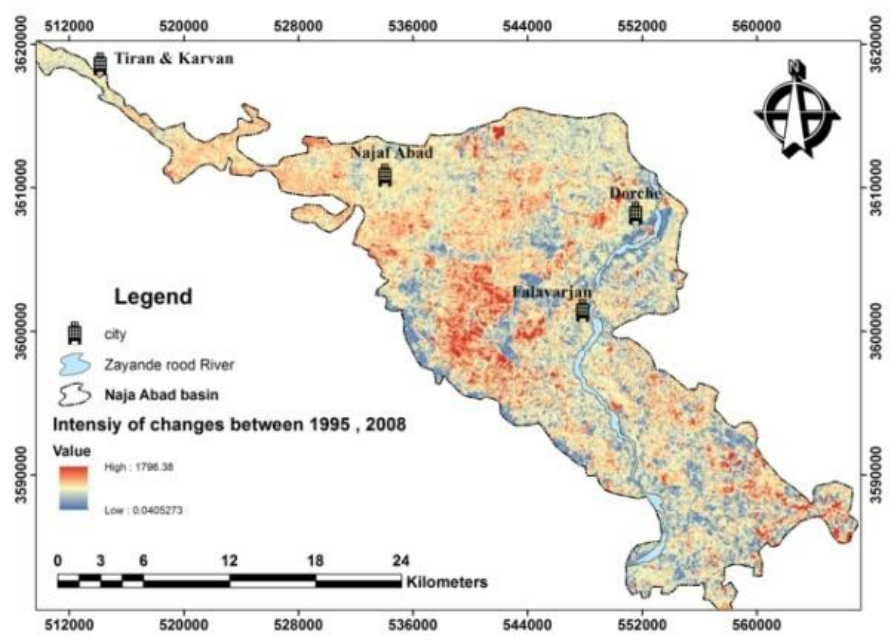

Figure 3. Change Vector image 1995-2008 (background scene: Brightness image 1995)

Vegetation areas show that this type of change, specifically with the increase in brightness values, indicate biomass obtain (i.e. Cultivate development). A more detailed analysis of the associated colour code suggests that each of these classes represents information related to more specific losses: red area related to clear cut of primary pastures and characterized mainly by subtle development of biomass (i.e. development caused by the reuse of former areas under growth). During the period 19901997, there is an intensive pressure for land occupation, because this region is relatively close to The Zayande Rood River (My results).

\subsection{Analysis of intensity of the change image $2008 / 2015$}

The Change Image referring to the period 2008/2015 (Figure 4), presents those elements which indicate an evolution on the land use/land cover processes. The north western regions in Figure 3, referring to the loss of biomass, appear now with less intensity. Southeast regions in previous image, related to the opening of small clearances in already occupied lots for subsistence agriculture of colonists.

Due to underground water losses and the reduction of water discharge in the years 2008 to 2015, areas around the Zayandehrood River become temporarily "cultivate development", providing a more performance of harvesting in the seven years of cultivation in these areas and showing small regeneration lots or the growth of crops. This is due to the fact that drought at this time of the year allows this kind of land use practice. During the second period, the area presents landscapes with higher complexity, because of the physical growth of urban areas; the development of agricultural lands and gardens; and the changing pattern of cultivation.

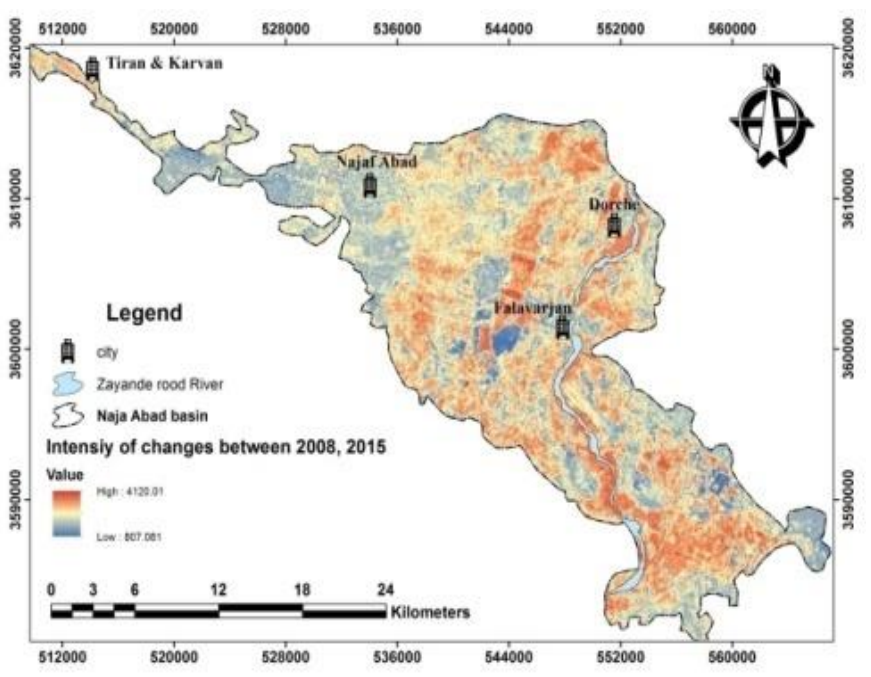

Figure 4. Change Vector image 2008-2015 (background scene: Brightness image 2008)

\subsection{Analysis of the change pixels $1995 / 2008$}

Figure 5 shows the unchanged pixels and changes pixel between 1995 to 2008. Green pixels are the ones that have changed in these years, appear now with more cultivation and evapotranspiration. The orange pixel is more punctually related to no changes in the value of evapotranspiration in these pixels. The southern and central areas have suffered more droughts. This is due to the development of cultivations, gardens and population growth and the development of urban green space and parks in these areas.

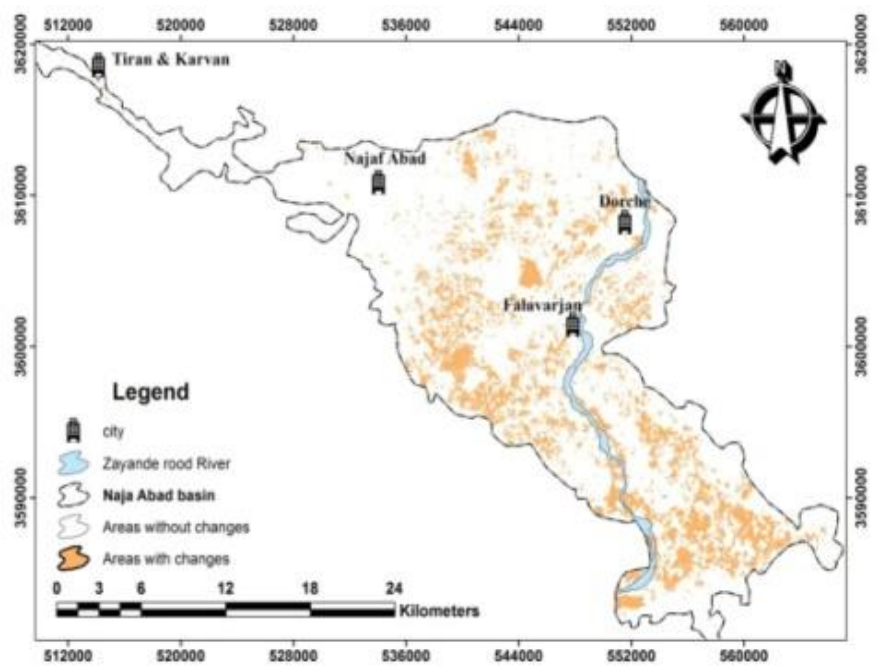

Figure 5. Zoning of unchanged pixels and changes pixel between 1995 to 2008 . 


\subsection{Analysis of the change pixels $2008 / 2015$}

Figure 6 presents the two different areas, Change and no change. Most of the area presents the no change (light brown areas).

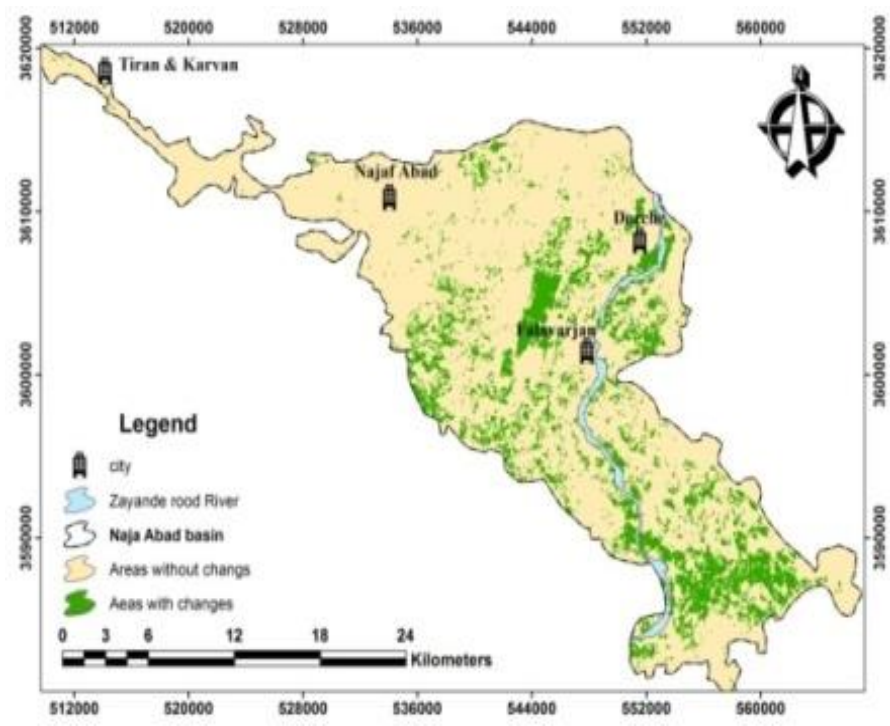

Figure 6. Zoning of unchanged pixels and changes pixel between 2008 to 2015

\subsection{Analysis of CVA}

The Change Image referring to the period 1995/2015 (Figure 7), presents those elements which indicate the pixels have suffered drought between 1995 and 2008 and ended their drought between 2008 and 2015 (green area).

The red areas show that pixels are beginning to drought. The biomass gain class, theoretically, indicates the area contained more vegetation in 2015 than it did in 2008. Practically, this can also be a conversion of the vegetation to other vegetative classes with higher spectral reflection and not necessarily an increase in vegetative biomass.

The white areas remain unchanged. More than 3-quarter of the study area falls in this category. This is probably due to the fact that most of the area still remains inaccessible or urban areas have been developed. The poor infrastructure coupled with the high population means that the pressure on the environment is limited.

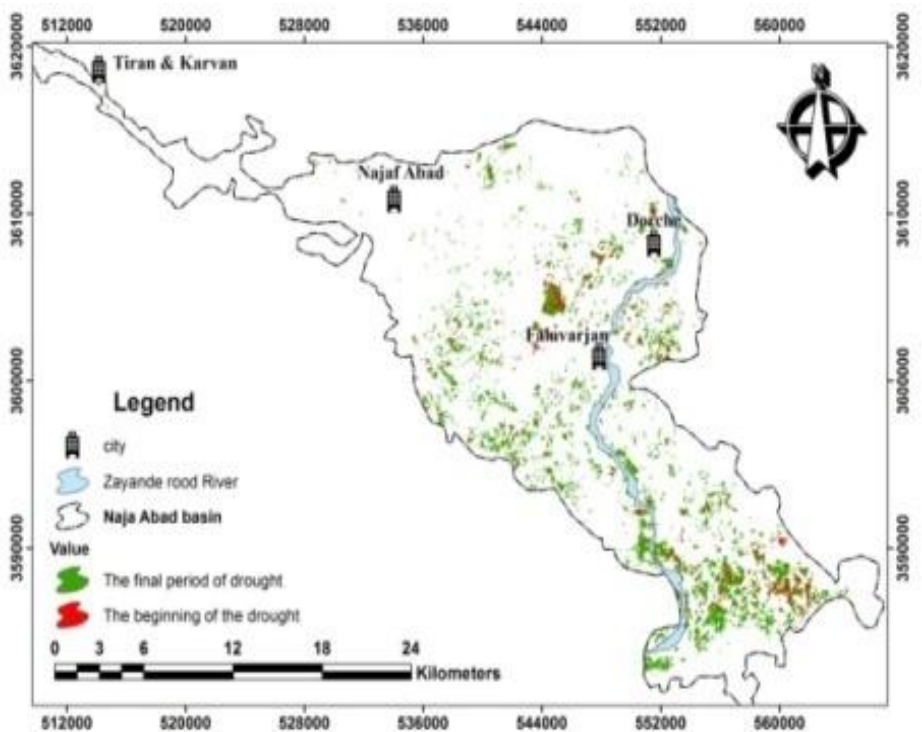

Figure 7. Zoning of drought condition pixels

\subsection{Accuracy assessment of CVA method}

There are almost 68891 pixels in evapotranspiration data which 12130 pixels changing was estimated by CVA technique between 1995 until 2008 and 12477 pixels changing belong to 2008 till 2015.

In order to evaluate CVA technique, accuracy assessment is very important and it has been computed using three different Landsat data for decision making process. Accuracy assessment includes overall accuracy, commission errors and Kappa coefficient (Xiaolu, 2011). It is obvious that CVA technique had 93\% accuracy assessment and 0.89 Kappa coefficient (table 1).

0.89 Kappa coefficient shows that there is great consistency between the results of CVA method and reference data. So it has been analyzed that CVA analysis can be useful tool for studying continuous change.

Table1. Kappa coefficient and Accuracy assessment

\begin{tabular}{llcccc}
\hline Reference change & & $\begin{array}{c}\text { Un-change } \\
\text { pixels }\end{array}$ & $\begin{array}{c}\text { Change } \\
\text { pixels }\end{array}$ & Sum & $\begin{array}{c}\text { Commission } \\
\text { error }\end{array}$ \\
\hline classified change & $\begin{array}{l}\text { Un-change } \\
\text { pixels }\end{array}$ & 50634 & 6126 & 56760 & $10.79 \%$ \\
& $\begin{array}{l}\text { Change } \\
\text { pixels }\end{array}$ & 5779 & 6351 & 12130 & $47.64 \%$ \\
& $\begin{array}{llll}\text { Sum } \\
\text { Commission } \\
\text { error }\end{array}$ & 56413 & 12477 & 230830 & \\
& $10.24 \%$ & $49.10 \%$ & & \\
& & & & &
\end{tabular}

Accuracy assessment $=93 \%$

Kappa coefficient $=0 / 89$

\section{CONCLUSIONS}

Spatial information on an ongoing drought are vitally important to mitigate its impacts. This paper presents a framework to identify the areas prone to drought in order to minimize the damages. Our results showed that 18 percent of pixels had been changed between 2008 to 2015 and almost $17 \%$ of pixels were modified from 1995 to 2008 . These outcomes were calculated by CVA method. Kappa coefficient of this analysis is 0.89 therefore 
there is high agreement between CVA results and reference images.

Comparative CVA products showed that evapotranspiration has increased between 1995 and 2008. Since one of the major government policy is to increase agricultural production, farmers forced to use more water and land conversion of grasslands to agricultural land. So the drought intensified between 1995 to 2008 but between 2008 to 2015 . This fact caused a decline in groundwater levels and water discharge wells have reduced the amount of agricultural production. So, evapotranspiration has reduced and the drought index is dropped.

\section{References}

Alesheikh, A., Sadeghi, A., Naeeni Fard, F., 2007. Design and Implementation of a Knowledge Based System to Improve Maximum Likelihood Classification Accuracy, Canadian Journal of Remote Sensing, 33(6), 459-467.

Arnon Karnieli ,Z. Q., Bo Wu , Panov, N., Feng Y., 2014. SpatioTemporal Dynamics of Land-Use and Land-Cover in the Mu Us Sandy Land, China, Using the Change Vector Analysis Technique. remote sensing 6, 9316-9339.

Bayarjargal, Y., A. K., Bayasgalan, M., Khudulmur, S., Gandush, C., Tucker, C. J., 2006. A comparative study of NOAA-AVHRR derived drought indices using change vector analysis, Remote Sensing of Environment 105, 9-22.

Bitelli, A. Z. a. G., 2017. A combined change detection procedure to study desertification using open source tools. Open_Geospatial Data, Software and Standards, 2-10.

Frank Thonfeldab, H., Matthias, B., Gunter, M., 2016. Robust Change Vector Analysis (RCVA) for multi-sensor very high resolution optical satellite data, International Journal of Applied Earth Observation and Geo information 50, 131-1.

Koch, R. N. S. B., 2008. Change vector analysis to categories land cover change processes using the tasselled cap as biophysical indicator, Environ Monit Assess (145), 227-23.

Jafari, M., Monavari, S. M., Majedi, H., Alesheikh, A. A., and Kheirkhah Zarkesh, M., 2016. Dynamic simulation of urban expansion based on cellular automata and logistic regression model: Case study of Hyrcanian region of Iran, Sustainability 8(8), 1-18.

Malila WA, L. W., 1980. Change Vector Analysis: An Approach for Detecting Forest Changes with Landsat. LARS Symp, 326335 .

Song Xiaolu, C. B., 2011. Change Detection Using Change Vector Analysis from Landsat TM Images in Wuhan, Procedia Environmental Sciences 11, 238 - 244.

SuYe, D. C., Yuab, J., 2016. A targeted change-detection procedure by combining change vector analysis and postclassification approach, Photogrammetric and Remote Sensing $114,115-124$

Vahidnia, M. H., Alesheikh, A, A., Behzadi, S., and Salehi, S., 2013. Modeling the spread of spatio-temporal phenomena through the incorporation of ANFIS and genetically-controlled cellular automata: A case study on forest fire, International Journal of Digital Earth, 6(1), 51-75.
Wen, X., 2009. Change Detection from Remote Sensing Imageries Using Spectral Change Vector Analysis.

Xinyu Fu, Z. T., Wu, J., McMillan, K., 2013. Drought planning research in the United States: An overview and outlook, International Journal of Disaster Risk Science 4(2): 51-58. 